\title{
URGENSI PENGELOLAAN SUMBERDAYA AIR DI KAWASAN WISATA SRI GETHUK KABUPATEN GUNUNGKIDUL
}

\author{
M. Widyastuti' ${ }^{1)}$, Ahmad Cahyadi' ${ }^{2}$, Tommy Andryan Tivianton ${ }^{3)}$ \\ 1,2,3 Jurusan Geografi Lingkungan, Fakultas Geografi, Universitas Gadjah Mada \\ Email: ahmadcahyadi@geo.ugm.ac.id
}

\begin{abstract}
ABSTRAK
Pariwisata di Kabuoaten Gunungkidul telah berkembang pesat sejak beberapa tahun belakangan ini. Perkembangan ini di antaranya ditandai dengan semakin banyaknya wisata alam selain objek wisata pantai, salah satunya adalah objek wisata Air Terjun Sri Gethuk. Aliran sungai yang mengalir menjadi air terjun di lokasi wisata ini berasal dari mata air kontak antara Formasi Wonosari dan Formasi Oya. Mata air tersebut selain mengalir ke air terjun juga digunakan untuk mengairi sawah dari penduduk. Makalah ini mengungkap pentingnya pengelolaan sumberdaya air di lokasi wisata Air Terjun Sri Gethuk, Kecamatan Playen Kabupaten Gunungkidul. Selain itu, makalah ini juga menawarkan beberapa alternative yang dapat ditempuh untuk menjamin keberlangsungan dua kegiatan (pariwisata dan pertanian) secara beriringan dan berkelanjutan. Selain itu, makalah ini akan membahas tentang langkah-langkah yang harus dilakukan untuk menjalankan rencana pengelolaan air berkelanjutan di lokasi kajian.
\end{abstract}

Kata Kunci: Pengelolaan Sumberdaya Air, Air Terjun Sri Gethuk

\section{A. PENDAHULUAN}

Perkembangan pariwisata di Kabupaten Gunungkidul beberapa tahun belakangan cukup pesat (Dinas Pariwisata Daerah Istimewa Yogyakarta, 2013). Perkembangan ini tidak lepas dari berkembangnya media informasi utamanya media sosial (Musadad, 2014). Perkembangan ini kemudian juga semakin banyak menyasar pariwisata alam selain pantai yang cukup banyak terdapat di Kabupaten Gunungkidul (Sudarmadji dkk., 2014).

Beberapa lokasi wisata alam dan minat khusus yang berkembang pesat di Gunungkidul adalah Gua Pindul, Kalisuci, Gunungapi Purba Nglanggeran dan Air Terjun Srigethuk. Perkembangan ini cukup menggembirakan mengingat sumbangan terhadap kesejahteraan daerah sekitar lokasi wisata cukup besar, serta menyumbang sekitar 6,1 miliar rupiah terhadap pendapatan asli daerah Kabupaten Gunungkidul (Sudarmadji dkk., 2014).

Perkembangan pariwisata alam dan minat khusus di Kabupaten Gunungkidul bukan berarti tanpa masalah. Beberapa objek wisata yang telah disebutkan bahkan menyebabkan beberapa konflik sosial yang cukup parah. Wisata Gua Pindul misalnya, telah menyebabkan banyak konflik social seperti banyaknya operator wisata, keberadaan calo pengantar pengunjung, serta perebutan lahan di lokasi wisata (Musadad, 2014).

Makalah ini mencoba untuk mengemukakan potensi konflik di lokasi wisata Air Terjun Srigethuk serta urgensi pengelolaan sumberdaya air dalam rangka mencegah terjadinya konflik dan berlangsungnya pembangunan yang berkelanjutan di lokasi wisata. Makalah ini juga 
mengungkapkan langkah-langkah yang dapat dilakukan untuk mencegah terjadinya konflik berdasarkan wawancara mendalam yang dilakukan penulis di lokasi kajian.

\section{B. POTENSI KONFLIK}

Air Terjun Srigethuk terletak di Desa Bleberan, Kecamatan Playen, Kabupaten Gunungkidul. Sumber air yang mengalir di Air terjun Srigethuk berasal dari sungai permukaan yang mengalir sepanjang tahun. Sungai permukaan tersebut ketika musim kemarau hanya memiliki sumber air yang berasal dari tiga mata air. Ketiganya merupakan mata air kontak yang muncul karena terjadi kontak Formasi Kepek (bagian atas) dengan Formasi Oya.

Sungai yang merupakan sumber Air Terjun Srigethuk dimanfaatkan pula untuk kegiatan pertanian, khususnya persawahan. Kondisi demikian memungkinkan terjadinya konflik kepentingan antara petani dan pengelola wisata. Pengelola wisata dalam hal ini memanfaatkan air dari sungai permukaan untuk mengalirkan ke air terjun sebagai objek utama dan kepentingan pemenuhan kebutuhan air untuk wisatawan (mandi, cuci, kakus, wudhu dan keperluan terkait usaha kuliner).

Potensi konflik mungkin muncul ketika musim kemarau. Hal ini karena pada saat tersebut, jumlah air relatif lebih sedikit, sehingga pemanfaatan air memerlukan pembagian yang baik agar semua sektor dapat terus menjalankan aktivitasnya. Saat ini pemanfaatan air dibagi dengan membangun bendungan yang mengatur aliran air ke masing-masing sektor yang memanfaatkan (Gambar 1). Koordinasi hanya dilakukan ketika akan melakukan perubahan, namun belum ada aturan-aturan khusus yang mengatur tentang pemanfaatan air ini.

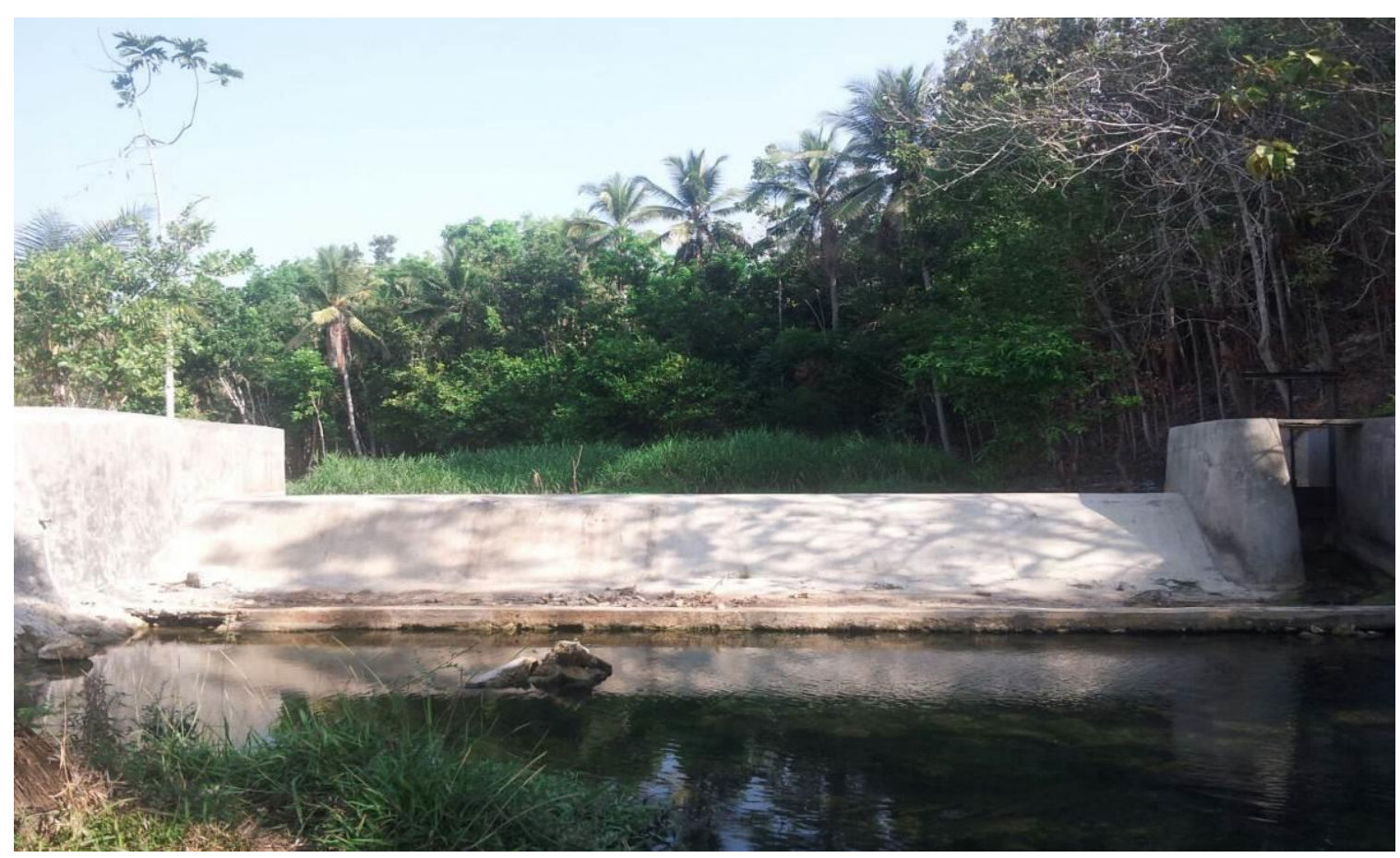

Gambar 1. Bendungan Pembagi yang Mengalirkan Sebagian Air Sungai ke Persawahan 
C. POTENSI KERUSAKAN MATA AIR

Salah satu aspek yang sangat penting dalam menjamin kelestarian mata air adalah kondisi daerah tangkapan air dari mata air. Kondisi geologis, topografis, vegetasi, penggunaan lahan dan klimatologis akan sangat mempengaruhi kondisi mata air di suatu wilayah. Kerusakan atau perubahan lahan akan berdampak pada kondisi mata air baik dari segi kualitas ataupun kuantitas.

Mata air yang mengalir ke Air Terjun Srigethuk memiliki karakteristik sebagai mata air kontak dengan lapisan bagian atas yang berfungsi menyimpan air berupa Formasi Kepek. Penggunaan lahan utama yang terdapat di daerah tangkapan air dari mata air tersebut berupa lahan milik Kementerian Lingkungan Hidup dan Kehutanan yang dikelola bersama dengan masyarakat. Tanamanan yang dibudidayakan di lokasi tersebut berupa kayu putih dengan perselingan palawija ketika musim penghujan (Gambar 2).

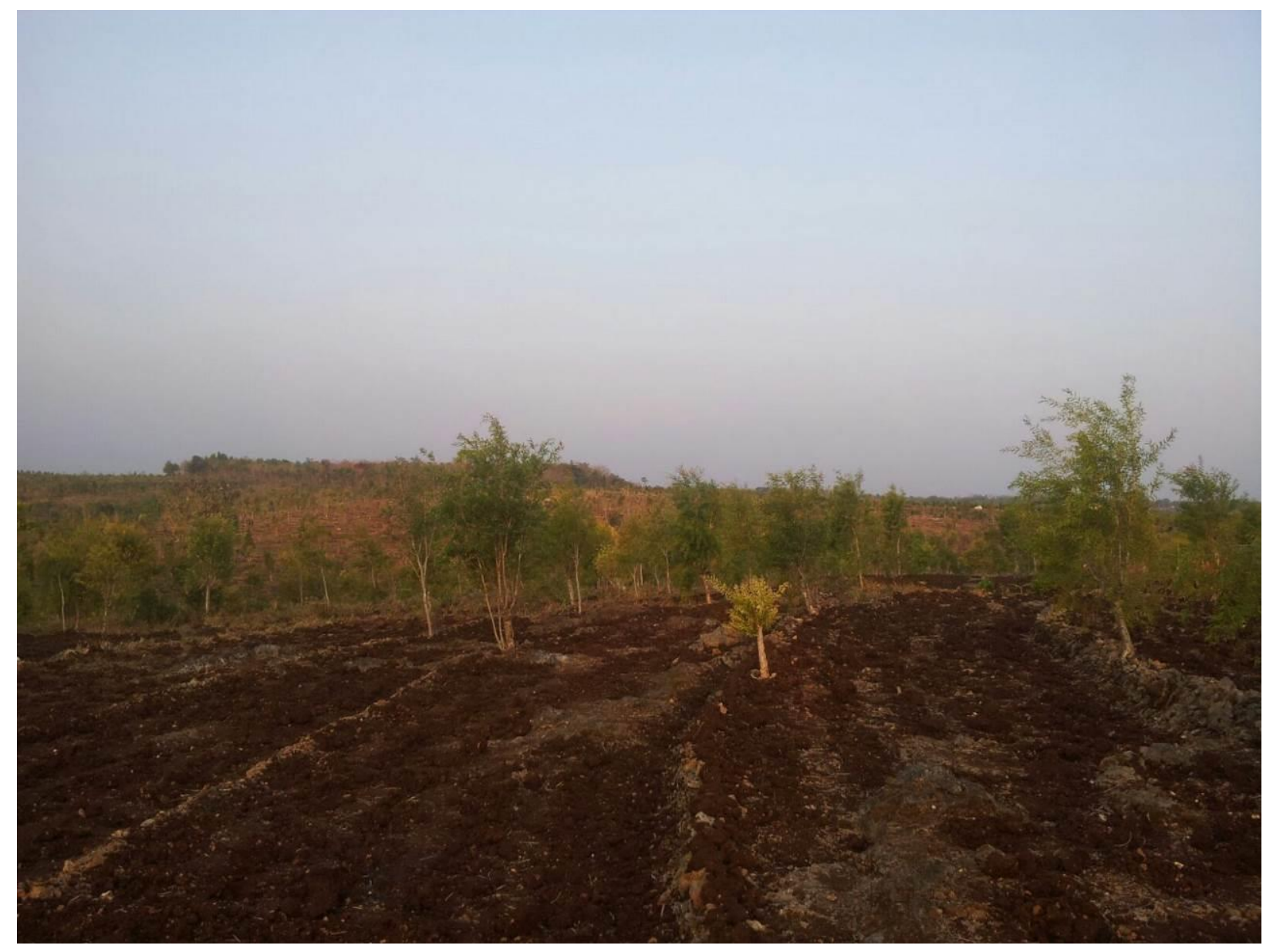

Gambar 2. Kondisi Daerah Tangkapan Air Mata Air di Air Terjun Srigethuk

Pengelolaan kayu putih dengan memangkas pohon menjadi pendek agar mudah dipanen, menyebabkan kanopi dari kayu putih sangat sedikit dan akan menyebabkan erosi yang besar ketika awal musim penghujan dan awal musim tanam yang kedua. Hal ini karena pada saat itu kondisi tanah tidak memiliki tutupan, sehingga tanah akan mudah mengalami erosi. Hal ini 
diperparah dengan kondisi lahan yang memiliki kemiringan yang cukup besar dengan penanganan erosi hanya berupa teras sederhana.

Beberapa penelitian terkait dengan dampak penanaman kayu putih terhadap kondisi hidrologis suatu daerah sudah cukup banyak dilakukan. Namun demikian, penelitian di Indonesia masih sangat sedikit dilakukan. Beberapa penelitian tersebut di antaranya; Ashton (1958), Doley (1967), Connor et.al. (1977), Attiwill (1980), Feller (1981) dan Chanie et.al. (2013). Beberapa penelitian tersebut ternyata menunjukkan bahwa penanaman huta kayu putih berdampak negatif ditinjau dari segi hidrologis.

Holmes dan Wronski (1971) dalam penelitiannya menjelaskan bahwa tanaman kayu putih telah menyebabkan rata-rata pengurangan input terhadap airtanah sebanyak $70 \mathrm{~mm} / \mathrm{tahun}$ lebih banyak dibandingkan tanaman tahunan. Lebih lanjut Holmes dan Wironski menjelaskan bahwa pada wilayah dengan curah hujan yang sama besarnya, tamanan tahunan akan menyebabkan pengurangan input airtanah (karena evapotranspirasi dan intersepsi) sebanyak 180 mm/tahun, sedangkan tamanan kayu putih menyebabkan pengurangan input terhadap airtanah sebanyak $250 \mathrm{~mm} /$ tahun. Hasil penelitian lain juga menunjukkan bahwa kelembaban tanah wilayah yang ditutupi oleh tanaman kayu putih ternyata lebih kering dibandingkan dengan wilayah dengan tutupan berupa tanaman pakis (Brookes dan Turner, 1964). Penelitian lain yang mendukung adalah penelitian Nicolls et. al. (1982) yang menyatakan bahwa semakin tua tanaman kayu putih, maka kehilangan air dalam suatu wilayah akan menjadi semakin besar.

Lima (1984) telah melakukan review terhadap banyak makalah dan penelitian yang dilakukan di berbagai penjuru dunia terkait dengahn pengaruh tanaman kayu putih terhadapa kondisi hidrologi suatu wilayah. Hasil kajian di antaranya menunjukkan bahwa evapotranspirasi yang dihasilkan dari masing-masing batang tanaman kayu putih ternyata sangat besar (Tabel 1). Selain itu, hasil kajian juga menunjukkan banyaknya presipitasi yang hilang akibat kehilangan air, sehingga debit sungai menjadi kecil (Tabel 2). Hal ini tentunya perlu disikapi dengan baik agar kedepannya kelestarian dari mata air dapat terjaga dan potensi konflik akibat semakiin sedikitnya debit sungai dapat dihindari. Kekhawatiran pantas muncul mengingat penelitian Chanie et.al. (2013) menyebutkan bahwa penanaman kayu putih di Ethiopia telah menyebabkan beberapa mata air mati. 


\section{PENUTUP}

Permasalahan terkait keberlanjutan sumberdaya air di Air Terjun Srigethuk terkait dengan pemanfaatan air untuk beberapa kepentingan yang berbeda, serta ancaman kerusakan daerah tangkapan air dari mata air yang memasok aliran sungai yang mengalir ke Air Terjun Srigethuk. Pengelolaan terkait dengan pembagian jumlah aliran air untuk beberapa kepentingan mesti dilakukan dengan melibatkan semua pihak yang terkait. Peraturan hendaknya dibuat secara tertulis dengan memuat hak dan keawajiban masing-masing pihak yang terkait serta sanksi-sanksi bagi pihak yang melanggar. Selain itu, diperlukan pengelolaan daerah tangkapan air yang lebih baik, sehingga keberadaan mata air senantiasa lestari dengan debit yang relatif tetap. Selain itu, pengelolaan wilayah tangkapan air mata air di Hulu Air Terjun Srigethuk perlu memperhatikan karakteristik tanaman dan mementingkan aspek hidrologis, kelestarian lahan dan ekonomi bagi masyarakat.

\section{E. DAFTAR PUSTAKA}

Ashton, D.H. 1958. The Ecology of Eucalyptus Regnans F.Muell; The Species and Its Frost Resistance. Australian journal of Botany, 6(2): 154-76.

Attiwill, P.M. 1980. Nutrient Cycling in A Eucalyptus Obliqua (L'Herit) forest. IV Nutrient Uptake and Nutrient Return. Australian Journal of Botany, 28: 199-111.

Brookes, J.D. dan Turner, J.S. 1964. Hydrology and Australian forest catchments. In: Water resources Use end Management Prociding. Melbourne University Press. 390-398.

Chanie, T.; Collick, A.S.; Adgo, E.; Lehmann, C.J. dan Steenhuis, T.S. 2013. Eco-hydrological impacts of Eucalyptus in the semi humid Ethiopian Highlands: the Lake Tana Plain. $J$. Hydrol Hydromech, 61(1): 21-29.

Connor, D.J.; Legge, N.J. dan Turner, N.C. 1977. Water Relations of Mountain Ash (Eucalyptus regnans, F. Muell) forests. Australian Journal of Plant Physiology, 4: 753-762.

Doley, D. 1967. Water relations of Eucalyptus marginata Sm. Under natural conditions. Journal of Ecology, 55(3): 597-614.

Sudarmadji; Marfai, M.A.; Cahyadi, A. dan Tivianton, T.A. 2015. Inisiasi Emergency Response System di Lokasi Wisata Minat Khusus Kalisuci, Gunungkidul. Jurnal Geografi dan Pendidikannya, 13(1): 14-25.

Lima, W.P. 1984. The Hydrology of Eucalypt Forest in Australia: A Review. IPEF, 28: 11-32.

Feller, M.C. 1981. Catchment Nutrient Budgets and Geological Weathering in Eucalyptus Regnans Ecosystems In Victoria. Australian journal Forest Ecology, 6: 65-77.

Musadad. 2014. Partisipasi Masyarakat Dusun Gelaran II dalam Pengembangan Wisata di Goa Pindul, Kabupaten Gunungkidul. Thesis. Yogyakarta : Sekolah Pascasarjana UGM. 
Holmes, J.W. dan Wronski, E.B. 1981. The Influence of Plant Communities Upon The Hydrology of Catchments. In: J.W. Holmes \& Talsma, T. (Eds). Land and Stream Salinity. New York: Elsevier Scientific Publishing.

Nicolls, K.D.; Honeysett, J.L. dan Graley, A.M. 1982. Soil Storage of Water Under Eucalypt

Forest in S.E. Tasmania. The National Symposium on Forest Hydrology, Melbourne.

\section{F. UCAPAN TERIMA KASIH}

Makalah ini merupakan bagian dari laporan hasil peklaksanaan kegiatan pengabdian masyarakat yang dibiayai lembaga penelitian dan pengabdian masyarakat (LPPM) Universitas Gadjah Mada melalui program Pengabdian Masyarakat Berbasis Implementasi Education for Sustainable Development dalam Masyarakat tahun 2015. Penulis mengucapkan terima kasih atas didanainya kegiatan dengan judul "Mewujudkan Masyarakat Tangguh Bencana Dalam Pengelolaan Wisata Berkelanjutan Berbasis Manajemen Bencana Melalui Inisiasi Early Warning System di Lokasi Air Terjun Srigethuk" ini. 